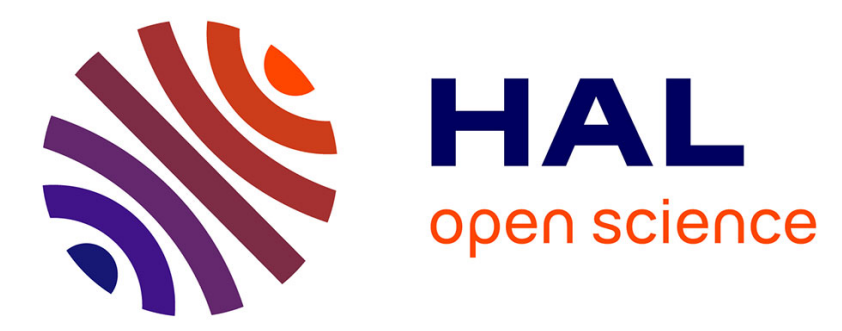

\title{
Modulation of the inflammatory response to LPS by the recruitment and activation of brown and brite adipocytes in mice
}

Patrick Munro, Océane Dufies, Samah Rekima, Agnès Loubat, Christophe Duranton, Laurent Boyer, Didier F Pisani

\section{To cite this version:}

Patrick Munro, Océane Dufies, Samah Rekima, Agnès Loubat, Christophe Duranton, et al.. Modulation of the inflammatory response to LPS by the recruitment and activation of brown and brite adipocytes in mice. AJP - Endocrinology and Metabolism, 2020, 319 (5), pp.E912-E922. 10.1152/ajpendo.00279.2020 . hal-02990250

\section{HAL Id: hal-02990250 \\ https://hal.science/hal-02990250}

Submitted on 17 Nov 2020

HAL is a multi-disciplinary open access archive for the deposit and dissemination of scientific research documents, whether they are published or not. The documents may come from teaching and research institutions in France or abroad, or from public or private research centers.
L'archive ouverte pluridisciplinaire HAL, est destinée au dépôt et à la diffusion de documents scientifiques de niveau recherche, publiés ou non, émanant des établissements d'enseignement et de recherche français ou étrangers, des laboratoires publics ou privés. 
4

5 Patrick Munro ${ }^{1}$, Océane Dufies ${ }^{1}$, Samah Rekima ${ }^{2}$, Agnès Loubat $^{2}$, Christophe Duranton $^{3}$, $6 \quad$ Laurent Boyer $^{1^{*}}$ and Didier F. Pisani ${ }^{3^{*}}$.

7

$81^{1}$ Université Côte d'Azur, Inserm, C3M, Nice, France.

92 Université Côte d'Azur, CNRS, Inserm, iBV, Nice, France.

$10{ }^{3}$ Université Côte d'Azur, CNRS, LP2M, Nice, France.

11 * Co-last authors

12 \$Correspondence: Didier Pisani, Laboratoire de PhysioMédecine Moléculaire, CNRS 


\section{Abstract.}

25 Objectives. Numerous studies have shown that the recruitment and activation of thermogenic 26 adipocytes, which are brown and beige/brite, reduces the mass of adipose tissue and 27 normalizes abnormal glycaemia and lipidaemia. However, the impact of these adipocytes on the 28 inflammatory state of adipose tissue is still not well understood, especially in response to 29 endotoxaemia, which is a major aspect of obesity and metabolic diseases.

30 Methods. First, we analysed the phenotype and metabolic function of white and brite primary 31 adipocytes in response to lipopolysaccharide (LPS) treatment in vitro. Then, 8-week-old male $32 \mathrm{BALB} / \mathrm{c}$ mice were treated for one week with a $\beta 3$-adrenergic receptor agonist (CL316,243, 1 $33 \mathrm{mg} / \mathrm{kg} / \mathrm{day}$ ) to induce recruitment and activation of brown and brite adipocytes and were 34 subsequently injected with LPS (E. coli lipopolysaccharide, i.p., $100 \mu \mathrm{g} / \mathrm{mouse}$ ) to generate 35 acute endotoxaemia. The metabolic and inflammatory parameters of the mice were analysed 6 36 hours later.

37 Results. Our results showed that in response to LPS, thermogenic activity promoted a local anti38 inflammatory environment with high secretion of IL-1RA without affecting other anti- or pro39 inflammatory cytokines. Interestingly, activation of brite adipocytes reduced the LPS-induced 40 secretion of leptin. However, thermogenic activity and adipocyte function were not altered by 41 LPS treatment in vitro or by acute endotoxaemia in vivo.

42 Conclusion. In conclusion, these results suggest an IL-1RA-mediated immunomodulatory 43 activity of thermogenic adipocytes specifically in response to endotoxaemia. This encourages 44 potential therapy involving brown and brite adipocytes for the treatment of obesity and 45 associated metabolic diseases.

47 Keywords. brown adipose tissue; white adipose tissue; cytokines; inflammation; 48 catecholamines. 


\section{Introduction}

White adipocytes are specialized for the storage and release of energy (carbohydrates and lipids), while brown adipocytes dissipate this energy in the form of heat (thermogenesis)

54 through the activity of uncoupling protein-1 (UCP1) (10). Brown adipocytes constitute brown 55 adipose tissue (BAT) but can also be found within white adipose tissue (WAT). They are then 56 called beige or brite adipocytes ("brown in white") and have a high thermogenesis capacity in 57 response to conditions such as prolonged cold exposure (11).

Overweight (body mass index, BMI $\geq 25 \mathrm{~kg} / \mathrm{m}^{2}$ ) and obesity $\left(\mathrm{BMI} \geq 30 \mathrm{~kg} / \mathrm{m}^{2}\right.$ ) are the consequences of a positive energy balance (energetic substrate storage $>$ expenditure) that 60 leads to an increase in the mass of subcutaneous and visceral white adipose tissue. Obesity is a

61 major risk factor for type 2 diabetes development, as $90 \%$ of patients suffering from type 2 62 diabetes are overweight or obese (16). It has also been shown that metabolic organs of obese 63 subjects, especially WAT, are characterized by low-grade inflammation that can lead to 64 metabolic disorders such as insulin resistance (20). Inflammation is characterized in WAT by an increase in inflammatory cytokines such as tumour necrosis factor $\alpha$ (TNFa), plasminogen activator inhibitor-1 (PAI-1) or interleukin-1 $\beta$ and -6 (IL-1 $\beta$ and IL-6). This promotes immune cell

67 infiltration of adipose tissue, particularly infiltration of inflammatory macrophages (29, 30). Immune cell accumulation and secretion of inflammatory cytokines affect adipose tissue homeostasis and, more specifically, the recruitment and function of adipocytes in WAT and BAT (32). Previous studies have shown that TNFa inhibits adipocyte differentiation (21) and that IL-

$711 \beta$ blocks insulin signalling, thus favouring insulin resistance (22). Recently, it has also been

72 shown that IL-1 $\beta$ and TNFa affect the thermogenic function of brown adipocytes $(18,34,39)$.

73 Altogether, these studies showed that inflammatory cytokines participate in the development of

74 an inflammatory environment, leading to the deregulation of adipose tissue homeostasis.

75 However, the origin of low-grade metabolic inflammation is still under debate. Growing evidence 
76 indicates that the gut microbiota is a major player in metabolic inflammation. The gut of obese 77 patients is characterized by an alteration in the microbiota (dysbiosis) and a disruption of the 78 intestinal barrier, increasing its permeability to microbiota metabolites and degradation products. 79 Consequently, systemic endotoxin levels increase (endotoxaemia), including the levels of 80 lipopolysaccharide (LPS) (46). It has been demonstrated using germ-free rodent models that this 81 endotoxaemia is directly linked to adipose tissue inflammation $(6,7,49)$. In this 82 pathophysiological condition, LPS directly activates Toll-like receptor 4 (TLR-4), which is 83 displayed by tissue macrophages and adipocytes (42). In response, white and brown/beige 84 adipocytes exhibit an altered function $(33,34)$ and secrete inflammatory cytokines (TNFa and IL$851 \beta$ ), which alter tissue homeostasis. Recently, it has been shown that brown and white 86 adipocytes respond differently to in vitro LPS stimulation and mediate different inflammatory 87 responses (13).

88 One of the strategies for treating type 2 diabetes associated with obesity is to increase 89 energy expenditure by stimulating the recruitment and activity of brown and/or beige adipocytes 90 (27). While little is known about the impact of this strategy on the balance and functionality of the 91 immune system, it is a key element in the pathology of metabolic syndrome, especially in low92 grade inflammation and inherent insulin resistance. In this work, we investigated the response of 93 white and brown/brite adipocytes to LPS treatment with regard to their impact on the 94 inflammatory environment induced by LPS. Using ex vivo and in vivo approaches in mice, we 95 demonstrated that recruitment/activation of brown/brite adipocytes by $\beta$-adrenergic receptor 96 agonists was not affected by LPS treatment and led to a reduced inflammatory response to LPS, 97 especially by the overexpression of an IL-1 receptor antagonist (IL-1RA), coded by II-1rn gene, 98 that is known to inhibit the action of $\mathrm{IL}-1 \beta$. 


\section{Materials and Methods}

101

\subsection{Reagents}

Culture media and buffer solutions were purchased from Lonza (Ozyme, St-Quentin en Yvelines, France), foetal bovine serum (FBS) was purchased from Eurobio (Courtaboeuf, 105 France), and insulin was purchased from Invitrogen (Cergy Pontoise, France). LPS (LPS-EK 106 Ultrapure isolated from E. coli K12 strain) was obtained from InvivoGen (Toulouse, France). 107 Other reagents were obtained from Sigma-Aldrich (Saint-Quentin Fallavier, France).

\subsection{Animals}

The experiments were conducted in accordance with the French and European regulations (2010/63/EU directive) for the care and use of research animals and were approved by national experimentation committees (MESR No.: APAFIS\#18322-2018121809427035 v2).

113 Eight-week-old male BALB/c mice from Janvier Laboratory (France) were maintained at housing 114 temperature $\left(22^{\circ} \mathrm{C}\right)$ on a 12:12-hour light-dark cycle, with ad libitum access to food and water.

The mice were treated daily with the $\beta 3$-adrenergic receptor agonist CL316,243 $(1 \mathrm{mg} / \mathrm{kg}$ 116 in saline solution, intraperitoneal injection, $n=12$ ) (Sigma-Aldrich) or with vehicle only (saline 117 solution, $n=12$ ). To induce endotoxaemia, 6 mice from each group were injected at day 7 with 118 LPS (100 $\mathrm{\mu g} /$ mouse in PBS, intraperitoneal) or vehicle only and were sacrificed 6 hours later 119 alternating one mouse from each group. At the end of the experiment, blood, interscapular 120 brown adipose tissue (iBAT), epididymal white adipose tissue (eWAT) and inguinal 121 subcutaneous white adipose tissue (scWAT) were sampled and used for different analyses. No 122 mice have been excluded.

123

\section{2.3. Cytokine and metabolic parameter quantification}


For blood analysis, freshly prepared plasma was diluted twice before analysis. For tissue analysis, freshly sampled WAT and BAT were washed in PBS, weighed and incubated in free

127 Dulbecco's modified Eagle's medium for 2 hours at $37^{\circ} \mathrm{C}$. The media were preserved for 128 analysis of various secreted proteins.

Leptin was assayed using a mouse leptin kit (Meso Scale Discovery, \# K152BYC), and cytokines were measured using a mouse V-PLEX pro-inflammatory panel 1 kit (\# K15048D)

131 according to the manufacturer's instructions using a QuickPlex SQ 120 apparatus (Meso Scale

132 Discovery, Rockville, Maryland, USA). IL-1RA levels were assayed using a mouse IL-1RA

133 ELISA kit (\#EMIL1RN) from Thermo Fisher Scientific (Courtaboeuf, France). Glycerol and 134 triglyceride determinations were performed using a dedicated kit (free glycerol reagent and 135 triglyceride reagent, Sigma Aldrich).

\section{2.4. Histology}

Freshly sampled tissues were fixed in $4 \%$ paraformaldehyde overnight at room temperature (RT) and then paraffin-embedded. Embedded tissues were cut into $5 \mu \mathrm{m}$ sections and dried overnight at $37^{\circ} \mathrm{C}$.

For histological analysis, the sections were stained with haematoxylin-eosin and mounted

142 in vectamount (Vecto laboratories).

143 For immunohistochemical analysis, antigen retrieval was performed in buffer low $\mathrm{pH}$ in a 144 de-cloaking chamber (Dako, S2367). The sections were then permeabilized in PBS with $0.2 \%$ 145 Triton X-100 at room temperature for $10 \mathrm{~min}$ and blocked in the same buffer containing $3 \%$ BSA 146 for 1 hour. The sections were incubated with rat anti-F4/80 antibody (Biorad, clone Cl:A3-1, 147 dilution $1: 100$ ) overnight at $4^{\circ} \mathrm{C}$. Following a 1 hour incubation with A568-coupled anti-rabbit 148 secondary antibodies, nuclear staining was performed with DAPI, and the sections were 149 mounted in PermaFluor mounting Media (Thermofisher). 
Visualization was performed with an Axiovert microscope. Images were captured using AxioVision software (Carl Zeiss, Jena, Germany).

\subsection{Stromal vascular fraction cell isolation and culture}

Subcutaneous WAT (scWAT, inguinal) and interscapular BAT (iBAT) deposits were sampled from 8-week-old BALB/c male mice, washed in PBS, and minced. Adipose tissue samples were digested for $45 \mathrm{~min}$ at $37^{\circ} \mathrm{C}$ in DMEM containing $2 \mathrm{mg} / \mathrm{ml}$ collagenase A (Roche

157 Diagnostics, Meylan, France) and $20 \mathrm{mg} / \mathrm{ml}$ bovine serum albumin (Sigma-Aldrich Chimie, Saint158 Quentin Fallavier, France). The sample was successively filtered through 250, 100 and $27 \mu \mathrm{m}$ 159 nylon sheets and centrifuged for $5 \mathrm{~min}$ at $500 \mathrm{~g}$. The pellet containing stromal vascular fraction 160 (SVF) cells was subjected to red blood cell lysis.

SVF cells were plated and maintained in DMEM containing 10\% Foetal Calf Serum until 162 confluence. Differentiation was induced in the same medium supplemented with $1 \mu \mathrm{M}$ dexamethasone, $0.5 \mathrm{mM}$ isobutylmethylxanthine and $860 \mathrm{nM}$ insulin for two days. Then, the cells were maintained for 7 days in the presence of $860 \mathrm{nM}$ insulin for white adipogenesis and $860 \mathrm{nM}$ insulin, $1 \mu \mathrm{M}$ rosiglitazone and $2 \mathrm{nM}$ triiodothyronine for brite and brown adipogenesis as previously published (36). Media were changed every other day. On the final day, the differentiated preadipocytes were stimulated with or without $1 \mu \mathrm{M}$ isoproterenol for 6 hours.

\subsection{Isolation and analysis of RNA}

Procedures were performed according to MIQE recommendations (5). Total RNA was extracted using a TRI-Reagent kit (Euromedex, Souffelweyersheim, France) according to the manufacturer's instructions. For RNA isolation from organs, tissues were homogenized in TRI-

173 Reagent using a dispersing instrument (ULTRA TURRAX T25). Reverse transcription174 polymerase chain reaction (RT-PCR) was performed using M-MLV-RT (Promega). SYBR qPCR 175 premix Ex Taq II from Takara (Ozyme, France) was used for quantitative PCR (qPCR), and 
assays were run on a StepOne Plus $A B I$ real-time PCR instrument (PerkinElmer Life and

177 Analytical Sciences, Boston). The expression of selected genes was normalized to that of the

178 TATA-box binding protein (TBP) and 36B4 housekeeping genes and then quantified using the

179 comparative- $\Delta$ Ct method. Primer sequences are available upon request.

180

$181 \quad$ 2.7. Oxygen consumption analysis

182 The oxygen consumption rate (OCR) and extra-cellular acidification rate (ECAR) of 10183 day-old differentiated SVF cells was determined using an XF24 Extracellular Flux Analyser 184 (Seahorse Bioscience, Agilent Technologies France, Courtaboeuf, France). Isoproterenol $(1 \mu \mathrm{M})$ 185 and/or LPS (100 ng/mL) were used to characterize inducible respiration. Uncoupled and 186 maximal OCR were determined using oligomycin (1.2 $\mu \mathrm{M})$ and carbonyl-cyanide-4187 (trifluoromethoxy)phenylhydrazone (FCCP, $1 \mu \mathrm{M})$. Rotenone and antimycin-A (2 $\mu \mathrm{M}$ each) were 188 used to inhibit mitochondrial respiration. All parameters were calculated as described previously 189 (4).

190

$191 \quad$ 2.8. Statistical analysis

Animal cohort size was determined using $G^{*}$ Power (14), and animals were allocated to 193 experimental groups by randomization. The data were analysed using GraphPad Prism 6 194 software and evaluated by ordinary one-way ANOVA followed by Tukey's multiple comparisons 195 post-test to assess significant differences between experimental groups. Differences were 196 considered statistically significant with $p<0.05$. The data are displayed as scatter plots of 197 independent values and group mean values \pm SD. 
3.1. In vitro phenotypic and functional metabolic response of white, brown and brite differentiated preadipocytes to LPS treatment

White and brite adipocytes were obtained after differentiation of preadipocytes that were isolated from the stromal vascular fraction of mouse subcutaneous white adipose tissue, and brown adipocytes from stromal vascular fraction of mouse brown adipose tissue, as previously published (36). On the last day of differentiation, the differentiated pre-adipocytes were treated for 6 hours with $1 \mu \mathrm{M}$ isoproterenol (a nonspecific $\beta$-adrenergic receptor agonist that activates lipolysis and/or UCP1 activity) and/or $100 \mathrm{ng} / \mathrm{ml}$ LPS and were then used for mRNA expression (Figure 1), or treated acutely with the same compounds for functional metabolism modification analysis (Figure 2).

LPS treatment did not alter perilipin 1, adiponectin and Glut4 mRNA expressions in all 212 kind of adipocytes. Leptin mRNA was scarcely detected in all adipocytes limiting our 213 interpretation about the strong inhibition found in white adipocytes under LPS and isoproterenol 214 treatments (Figure 1). White adipocytes barely expressed Ucp1 and perilipin 5 mRNA, and LPS 215 and isoproterenol did not alter these expression levels. In brite adipocytes, perilipin 5 which was 216 slightly inhibited by LPS treatment independent of isoproterenol. Interestingly, LPS alone did not 217 alter Ucp1 expression in brite adipocytes but blunted the increase in Ucp1 mRNA expression 218 due to acute isoproterenol treatment (Figure 1). In brown adipocytes, perilipin 5 and Ucp1 mRNA 219 levels were increased by isoproterenol but unaffected by LPS. Interestingly, in all kinds of 220 adipocytes Ppary (peroxisome proliferator-activated receptor $\mathrm{Y}$ ) mRNA levels were inhibited by 221 LPS and by isoproterenol treatment (Figure 1).

Analysis of Tnfa and II-6 mRNA levels showed that they were overexpressed after acute

223 LPS treatment. Interestingly, isoproterenol completely inhibited Tnfa overexpression in the three 224 kinds of adipocytes. A more complex situation was found for II-6 mRNA, which was positively 
affected by the combination of isoproterenol and LPS treatment in white adipocytes but inhibited by the same cotreatment in brite and brown adipocytes (Figure 1). Analysis of II-1 $\beta$ mRNA expression showed an increase after LPS treatment of adipocytes. Isoproterenol did not alter this expression except when white adipocytes were treated with both isoproterenol and LPS. As II-1 $\beta$ mRNA encodes the pro-form of the protein before its maturation and secretion, these results need to be analysed with caution. mRNA expression of II-1rn, which codes for the IL-1RA protein that counteracts the effect of IL-1 $\beta$, was increased after LPS treatment, similar to that of II-1 $\beta$ mRNA. Interestingly, brite adipocytes expressed more $I I-1 \mathrm{rn}$ than white and brown adipocytes. This expression in brite adipocytes was increased by LPS treatment and, more importantly, by isoproterenol with or without LPS (Figure 1).

At the metabolic level, isoproterenol treatment induced glycerol release (a reflection of 236 lipolysis) in the three types of adipocytes, but cotreatment with LPS had no effect (Figure 2A). 237 Interestingly, LPS slightly but significantly increased glycerol release in white, brite and brown 238 adipocytes. The extracellular acidification rate (ECAR) (Figure 2B) and oxygen consumption rate 239 (OCR) (Figure 2C) were analysed concomitantly and were increased by acute isoproterenol treatment in brite and brown adipocytes, while only the OCR was increased in white adipocytes.

241 Uncoupling mitochondrial oxygen consumption (the OCR due to proton leakage) was increased 242 in brite and brown adipocytes after isoproterenol stimulation, which is a reflection of Ucp1 activity 243 (Figure 2C). Neither ECAR nor OCR was affected by LPS treatment (Figure 2B-C).

244 Taken together, these in vitro adipocyte experiments suggest that activation of adipocyte $245 \beta$-adrenergic receptors decreased the inflammatory phenotype and that LPS treatment did not 246 clearly affect the thermogenic phenotype. ß3-adrenergic receptor agonist (CL316,243) 
Eight-week-old male BALB/c mice were treated daily with a $\beta 3$-adrenergic receptor agonist (CL316,243, $1 \mathrm{mg} / \mathrm{kg}$ ) that activates brown and brite adipocyte thermogenesis and adipocyte lipolysis and were finally treated with $100 \mu \mathrm{g}$ of LPS for 6 hours. Body weight was unaffected by treatment with CL316,243 or LPS (Figure 3A). Different weights of epididymal WAT showed that fat mass was decreased after CL316,243 treatment but was unaffected by LPS treatment (Figure 3A). While the plasma glycerol level did not change, we found a decrease in plasma triglyceride levels, probably due to the high use of this substrate by activated brown and brite adipocytes (Figure 3B). Interestingly, LPS treatment also decreased triglyceride levels, but no additive effect was found in the cotreated mouse group (Figure 2B). Leptin plasma levels increased in LPS-treated mice, and the effect was blunted when the mice were pre-treated with CL316,243 (Figure 3C). The same kind of results were found for secreted leptin using scWAT explants sampled from these mice (Figure 3C). Thus, in our experiment, leptin levels did not follow the fat mass of the animals and corresponded to an adipose tissue inflammatory response 263 to LPS.

To assess the effects of acute LPS treatment on brown and brite adipocyte recruitment and activation, we performed histological and molecular analyses of WAT and BAT from mice in each group. As shown in Figure 3D, CL316,243 decreased quantity of lipid droplets in brown adipose tissue and slightly increased Ucp1 and Cpt1m (Carnitine O-Palmitoyltransferase 1M) mRNA expression, which is characteristic of activated BAT, without affecting Perilipin 1 and 5 expressions as well as adiponectin, Glut4 (glucose transporter 4) and Ppary mRNA expressions (Supplementary Figure 1A). scWAT histological sections from CL316,243-treated groups displayed massive recruitment of multiloculated adipocytes (Figure 3D), which is a characteristic morphology of brite adipocytes. This was confirmed by the overexpression of Ucp1 and Perilipin 2735 mRNA (Supplementary Figure 1B).

Perilipin 1, adiponectin and Leptin mRNA expression in scWAT did not change with LPS 
expression supports an acute response independent of fat mass change (Supplementary Figure 1B). Differently to Glut4 mRNA which was increased after isoproterenol treatment and less affected by LPS treatment, Ppary mRNA levels were strongly inhibited by LPS independently to isoproterenol exposition (Supplementary Figure 1B). Interestingly, we did not detect cell infiltration or crown structure after LPS treatment by histological analysis (Figure 3D), which was confirmed by negative staining for the macrophagic marker F4/80 (data not shown). Certainly,

282 the time was too short between LPS treatment and analysis to allow infiltration of adipose tissue 283 by immune cells.

3.3. Acute LPS treatment induces an inflammatory response and secretion of antiinflammatory cytokines.

Inflammation is mainly triggered by inflammatory cytokine secretion, followed by a resolution step that is characterized by secretion of anti-inflammatory cytokines. This effect was observed in mice that were treated with LPS. Terminal LPS treatment induced an increase in the plasma level of IL-1 $\beta$, as well as IL-1 $\beta$ secretion in BAT and scWAT explants, and CL316,243 291 did not alter this effect (Figure 4A). IL-1RA plasma levels equivalently increased after 292 administration of LPS to untreated and CL316,243-treated mice (Figure 4B). In contrast, in 293 scWAT and BAT, while LPS treatment increased IL-1RA secretion, CL316,243 also increased 294 IL-1RA secretion, and this effect was additive in the presence of LPS (Figure 4B). levels were increased after LPS treatment independent of CL316,243 treatment, and the same trend was found for IL-6 (Supplementary Figure 2). KC/GRO (CXCL-1) was detected in the plasma of mice but was not affected by the different treatments. Interestingly, LPS-induced IFNY and IL-2 plasma levels increases were abrogated when the mice were treated with CL316,243 300 (Supplementary Figure 2). 
A different profile of secreted cytokines was found in the adipose tissue explant media.

302 IFNy was undetected, and IL-2 and IL-12 were barely detected (Figure 5), with a slight increase only in the iBAT of LPS-treated mice (Figure 5A). Secreted IL-6 increased in the iBAT of LPStreated mice independent of CL316,243 treatment and only in LPS plus CL316,243 in scWAT (Figure 5). In contrast, KC/GRO and TNFa increased in all groups of LPS-treated mice independent of CL316,243 treatment and had the same trend (Figure 5).

Although the anti-inflammatory cytokine IL-4 was barely detected in plasma and undetected in explants of adipose tissues, the plasma level of IL-10 was increased in response to LPS (Supplementary Figure 3). None of these were altered by CL316,243. In contrast, local secretion of IL-10 by adipose tissue was not stimulated by LPS alone, but an increasing trend was observed after CL316,243 treatment, especially in BAT that was cotreated with LPS 312 (Supplementary Figure 3).

\section{Discussion}

Metabolic endotoxaemia, found for example in obese patients and sepsis, appears after gut epithelium disturbance which allows LPS from gram-negative gut bacteria to enter the systemic circulation $(8,24)$. This leads to systemic and local inflammation, which is among others a central feature of metabolic syndrome development (6). Several studies have shown the action of LPS on white and brown adipocyte differentiation and function. LPS modulates adipocyte functions directly via TLR-4 activation or indirectly, especially through macrophage activation which in turn secrete cytokines that modulate adipocyte functions. In WAT, LPS directly induces lipolysis (51) and cytokine secretion by adipocytes and indirectly (mainly by 324 macrophage-derived cytokines) inhibits differentiation and promotes insulin resistance $(41,50)$. 325 In BAT, LPS has been suspected to be an activator of brown adipocyte thermogenesis (9), but 326 recent studies demonstrated that acute (in vitro) and chronic (in vivo) exposure to LPS inhibits 
UCP1 expression and function in these adipocytes $(1,33)$. However, little is known about the influence of white and brite or brown adipocytes on local and systemic inflammation due to LPS exposure, especially the secretion of inflammatory mediators such as cytokines and adipokines. Herein, we analysed the impact of brown and brite adipocyte recruitment and activation on systemic and local (adipose tissue) responses to acute LPS treatment, which mimics 332 endotoxaemia.

Leptin is a well-known modulator of pyrexia in response to LPS $(15,37,38)$. We found an expected increase in leptin secretion in plasma that correlated with scWAT leptin level, a chief origin of this adipokine with others adipose tissues (25), in mice that were stimulated with acute

336 LPS treatment. This positive effect was not found at the mRNA level in the scWAT of these mice 337 or in primary white adipocytes that were exposed to LPS. These results suggested that the 338 modulation in leptin levels were not due to change in adipose tissue mass, but that LPS 339 stimulated adipocyte leptin secretion without affecting its mRNA expression. Interestingly, these 340 increased leptin levels were completely abolished when the mice were pre-treated with 341 CL316,243, which induces brown/brite adipocyte recruitment and activation and thus 342 thermogenesis. As leptin induces fever independently of thermogenesis (15), we suspect 343 negative feedback that prevents hyperthermia due to the addition of thermogenesis and pyrexia. 344 Unfortunately, leptin levels cannot be related to fever, as body temperature was not available in 345 our work. Inconsistently, numerous studies have shown an inhibitory effect of chronic LPS 346 treatment on Ucp1 expression and function in vivo and thus on thermogenesis (33). In our work, 347 we showed that LPS did not modify Ucp1 expression or the histology of BAT and scWAT after 348 CL316,243 treatment, strongly suggesting that LPS does not affect thermogenesis. The 349 difference between our results and those of Okla and colleagues is probably due to the duration 350 of LPS treatment (6 hours vs. 2 weeks) (33). This was confirmed by an in vitro experiment on 351 brite adipocytes showing that LPS slightly inhibited Ucp1 mRNA expression due to isoproterenol 352 treatment but did not modify Ucp1 function, as demonstrated by oxygen consumption analysis. It 
353 is possible that a difference exists between brite and brown adipocytes, as LPS inhibits Ucp1 354 function in brown adipocytes in vitro (1).

As mentioned previously, LPS is a known inducer of lipolysis which is confirmed in our in vitro experiment (51). In the same way, thermogenic activity induced by CL316,243 treatment 357 involved a sustained lipolysis supplying fatty acids as energy substrate to brown and brite 358 adipocytes and releasing glycerol in circulation (47). In vivo, we did not detect any increase in 359 glycerol plasma level both after LPS and CL316,243 treatment. While the short treatment time 360 with LPS can explain this, it is not the case for chronic CL316,243 treatment. We hypothesized 361 that, in this mouse strain, a higher uptake of glycerol by liver or an active glycerol recycling by 362 adipocytes, could limit level of circulating glycerol in the blood $(3,35)$.

Dowal and colleagues used coculture of human adipocytes and macrophage cell lines to 364 show that brown adipocytes reduced macrophage IL-6 secretion in response to LPS compared 365 to that of white adipocytes (13). Under similar conditions, mRNA expression of other 366 inflammatory markers, including II-10, in macrophages was inhibited by brown adipocytes. 367 These results suggest that brown adipocytes and perhaps brite adipocytes display general 368 immunomodulatory properties of interest. Our ex vivo analysis showed the same results, with decreased mRNA expression of II-6 in brite adipocytes compared to that in white adipocytes and to a lesser extent for Tnfa. We hypothesised that the inhibition of inflammatory cytokine expression in brown adipocytes participates in its immunomodulatory activity on macrophages.

372 Unfortunately, this inhibition of pro-inflammatory and anti-inflammatory cytokine levels was not 373 confirmed in vivo. Control mice and mice that were pre-treated with CL316,243 displayed an 374 equivalent increase in the secretion of TNFa and IL-6 after LPS treatment. The same results 375 were obtained for other pro- and anti-inflammatory cytokines in plasma and adipose tissue, 376 except for IFNy and IL-2 plasma levels, which were strongly decreased in the CL316,243 group 377 after LPS treatment. As no IFNy and very low quantities of IL-2 were found in BAT and scWAT, 378 we can exclude the involvement of these tissues in this immunomodulatory effect. Moreover, the 
discrepancies between plasma and adipose tissue cytokine levels demonstrated that the local production of cytokines found in the adipose tissue had a limited impact on systemic inflammatory response to LPS. Nevertheless, in addition to cytokines, oxygenated derivatives of $\omega 6$ polyunsaturated fatty acids ( $n-2$ series prostaglandins and $n-4$ series leukotrienes) and of $\omega 3$ polyunsaturated fatty acids ( $n-3$ series prostaglandins, $n-5$ series leukotrienes, resolvins (Rv) and protectins) are highly synthesized and secreted by adipocytes, and participate in the inflammatory and resolutive state of immune response $(19,31)$. As we have demonstrated previously that recruitment and activation of brown and brite adipocytes modulate these syntheses $(12,17)$, we can hypothesize that these metabolites could participate to local, and even systemic, inflammatory response to LPS of the adipose tissue.

Along pro-inflammatory cytokines, IL-1 $\beta$ has a central role in the immune response to LPS and in adipose tissue homeostasis (45). More specifically, IL-1 $1 \beta$ secretion induced by LPS treatment disrupts insulin signalling in WAT $(2,22,26)$ and inhibits UCP1 function in BAT both in vitro and in vivo $(9,18)$. As expected, we found that LPS treatment induced IL-1 $\beta$ production in 393 all conditions assayed, as shown by mRNA expression in white and brite adipocytes in vitro and 394 secretion of the mature form of IL-1 $\beta$ in BAT and scWAT in vivo. In addition, we showed that 395 recruitment and activation of brown and brite adipocytes did not modulate IL-1 $\beta$ levels and thus 396 did not seem to prevent inflammatory action of this cytokine. IL-1 $\beta$ is mainly regulated at the 397 expression, maturation and secretion levels, especially by modulation of the NF-kB transcription 398 factor and activation of inflammasomes. Another pathway exists to modulate IL-1 activity, which 399 is the production and secretion of IL-1RA. This cytokine antagonizes the biological effects of IL$4001 \beta$ by competing for binding to the IL-1 receptor without inducing a cellular response (43). 401 Moreover, IL-1RA is highly produced by adipose tissue (23). Interestingly, we demonstrated that 402 II-1rn mRNA was more highly expressed in brite adipocytes in vitro than in white adipocytes and 403 that this difference was amplified when the cells were treated with a $\beta$-adrenergic receptor 404 agonist. Importantly, these observations were confirmed in vivo, where CL316,243 treatment 
increased IL-1RA levels in WAT and BAT, with or without LPS treatment. In contrast, plasma levels of IL-1RA increased only in the presence of LPS and independently of CL316,243 treatment. Taken together, these results clearly demonstrate that brite and brown adipocytes express and/or secrete more IL-1RA than white adipocytes, especially in response to acute LPS treatment and certainly via direct activation of TLR4 pathway. In addition to a potential antiinflammatory role of IL-1RA, we hypothesise that the simultaneous secretion of IL-1RA and IL-

$4111 \beta$ corresponds to a protective mechanism to preserve adipocyte function in an inflammatory 412 context.

Increased IL-1 $\beta$ or decreased IL-1RA levels are linked to the development of obesity and 414 diabetes, and among therapeutic strategies developed to normalize these levels, some studies 415 have focused on the use of exogenous IL-1RA $(44,45)$. In rodents, chronic IL-1RA treatment of 416 mice that were fed a high-fat/high-sucrose diet prevented glucose metabolism alteration and 417 normalized the metabolic parameters linked to obesity without affecting fat mass (40). In 418 addition, using IL-1RA-overexpressing mice, we detected a normalization of inflammatory 419 marker mRNA in the WAT of mice fed a high-fat diet (40). In humans, several clinical trials using 420 anakinra (recombinant human IL-1RA) have been developed with obese and diabetic patients 421 and have shown, among others, better pancreatic function and decreased systemic inflammation 422 after treatment $(28,48)$. As we demonstrated that IL-1RA adipose levels are increased after $\beta$ 423 adrenergic receptor agonist treatment, we suggest that increasing brown/brite adipocyte 424 recruitment and activity in humans, in addition to decreasing fat mass, protects adipose tissue 425 from the adverse effects of IL-1 $\beta$.

426 Our study was performed in lean BALB/c mice at ambient temperature. Thus, i) we 427 cannot exclude that the results displayed herein was inherent to the model chosen; ii) we have a 428 basal thermogenic activity due to ambient temperature which could limit the difference between 429 CL316,243 treated and untreated mice and it will be interesting to reproduce this work at 430 thermoneutrality to match more the human situation; iii) as we have decided to develop our 
431 study on lean mice in order to exclude any additional effect of obesogenic environment, it will be 432 of interest to transpose now this study in an obese mouse model mimicking human situation 433 where endotoxaemia is mainly found.

434 Finally, we have demonstrated that recruitment and activation of brown and brite 435 adipocytes in the adipose tissue of mice led to a local anti-inflammatory phenotype characterized 436 by an increased IL-1RA level and decreased leptin secretion in response to endotoxaemia 437 without modulation of systemic inflammation.

438

439 
440 Acknowledgments. The authors greatly acknowledge the C3M Animal core facility, the IRCAN 441 Cytomed platform and the IBV histology platform. This research was funded by INSERM, Region 442 PACA and Société Francophone du Diabète (SFD)/Pierre Fabre Médicament 2017.

444 Author Contributions. Conceived and designed the experiments: L.B., D.F.P. Performed the 445 experiments: P.M., O.D., S.R., A.L., C.D., D.F.P. Analysed the data: P.M., C.D., L.B., D.F.P. 446 Wrote the manuscript: P.M., C.D., L.B., D.F.P. All authors have revised and finally approved the 447 manuscript.

449 Competing Interests. The authors declare no conflict of interest. 
Legends.

452 Figure 1. Effect of LPS on white, brite and brown differentiated preadipocytes in vitro. White and brite adipocytes were obtained after differentiation of stromal vascular fraction cells isolated from mouse scWAT, and brown adipocytes from stromal vascular fraction of iBAT. mRNA expression analysis by qPCR of white (leptin, perilipin 1, Ppary, Glut4 and Adiponectin), brite/brown (Ucp1 and perilipin 5) and inflammatory markers (Tnfa, II-6, II-1 $\beta$, and II-1rn) after 6 hours of treatment with isoproterenol $(1 \mu \mathrm{M})$ and/or LPS $(100 \mathrm{ng} / \mathrm{ml})$. The results are displayed as the mean \pm SEM. $n=6$ (2 replicates of 3 independent cultures). ${ }^{*} p<0.05$ vs. control; $\$$ $p<0.05$ vs. LPS; $\S p<0.05$ vs. isoproterenol; $£ p<0.05$ vs. white adipocytes.

\section{Figure 2. Effect of LPS on white, brite and brown differentiated preadipocytes in vitro.} White and brite adipocytes were obtained after differentiation of stromal vascular fraction cells isolated from mouse scWAT, and brown adipocytes from stromal vascular fraction of iBAT. (A) Glycerol levels were assayed in the supernatants of white and brite adipocytes that were treated for 2 hours with LPS and/or isoproterenol. (B-C) Adipocytes were analysed for oxygen consumption and extracellular acidification following sequential injection of isoproterenol and/or LPS, oligomycin A $(1.2 \mu \mathrm{M})$ and rotenone/antimycin $A(2+2 \mu \mathrm{M})$. (B) ECAR in response to LPS and/or isoproterenol is displayed as \% of basal ECAR. (C) Plots show mitochondrial OCR and the indicated injections. Histograms display mitochondrial OCR in response to LPS and/or isoproterenol (induced/basal mitochondrial OCR) and uncoupling mitochondrial respiration. The results are displayed as the mean \pm SEM. $n=6$ (2 replicates of 3 independent cultures). * $p<0.05$ vs. control; $\$ p<0.05$ vs. LPS; $\S p<0.05$ vs. isoproterenol; $£ p<0.05$ vs. white adipocytes. 
477 epididymal white adipose tissue (eWAT) weights, (B) triglycerides and glycerol plasma levels 478 and (C) secreted leptin levels in plasma and subcutaneous white adipose tissue (scWAT). (D) 479 Haematoxylin-eosin staining of interscapular BAT (iBAT), scWAT and eWAT sections. The 480 results are displayed as independent values (dots) and the mean \pm SE. $n=6$ (mice and plasma) 481 or 8 (explant). ${ }^{*} p<0.05$.

482

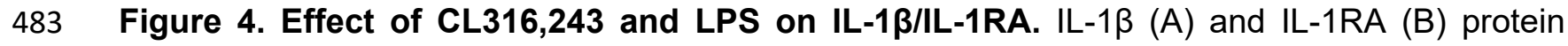
484 levels were assessed in plasma (upper panel) and in the media of iBAT (middle panel) and 485 scWAT (lower panel) explants from mice that were treated for 1 week with CL316,243 daily (1 $486 \mathrm{mg} / \mathrm{kg} / \mathrm{day})$ or vehicle only $(\mathrm{NaCl})$, and with or without LPS treatment $(1 \mathrm{mg} / \mathrm{kg})$ for the final 6 487 hours. The results are displayed as independent values (dots) and the mean \pm SE. $n=6$ 488 (plasma) or 8 (explant). ${ }^{*} p<0.05$. 489

490 Figure 5. Local inflammatory response to LPS. IFNy, TNFa, IL-6, IL-12-p70, KC/GRO (CXCL491 1) and IL-2 levels were assessed in the media of iBAT (A) and scWAT (B) explants from mice 492 that were treated for 1 week with CL316,243 daily (1 mg/kg/day) or vehicle only ( $\mathrm{NaCl})$, and with 493 or without LPS treatment $(1 \mathrm{mg} / \mathrm{kg})$ for the final 6 hours. The results are displayed as explant 494 values (dots) and the mean \pm SE. $\mathrm{n}=8 .{ }^{*} p<0.05$.

495

496

497 
501 Chen J, and Zhao L. Activation of pattern recognition receptors in brown adipocytes induces inflammation and suppresses uncoupling protein 1 expression and mitochondrial respiration. Am J Physiol Cell Physiol 306: C918-930, 2014. pathogenesis and treatment of metabolic disease: Focus on adipose tissue inflammation and insulin resistance. Cytokine 75: 280-290, 2015.

507 3. Barquissau V, Beuzelin D, Pisani DF, Beranger GE, Mairal A, Montagner A, Roussel B, Tavernier 508 G, Marques MA, Moro C, Guillou H, Amri EZ, and Langin D. White-to-brite conversion in human adipocytes promotes metabolic reprogramming towards fatty acid anabolic and catabolic pathways. Molecular metabolism 5: 352-365, 2016.

4. Brand MD, and Nicholls DG. Assessing mitochondrial dysfunction in cells. Biochem J 435: 297312, 2011. MW, Shipley GL, Vandesompele J, and Wittwer CT. The MIQE guidelines: minimum information for publication of quantitative real-time PCR experiments. Clin Chem 55: 611-622, 2009.

6. Cani PD, Bibiloni R, Knauf C, Waget A, Neyrinck AM, Delzenne NM, and Burcelin R. Changes in gut microbiota control metabolic endotoxemia-induced inflammation in high-fat diet-induced obesity and diabetes in mice. Diabetes 57: 1470-1481, 2008.

7. Cani PD, and Delzenne NM. Involvement of the gut microbiota in the development of low grade inflammation associated with obesity: focus on this neglected partner. Acta Gastroenterol Belg 73: 267269, 2010.

8. Cani PD, Delzenne NM, Amar J, and Burcelin R. Role of gut microflora in the development of obesity and insulin resistance following high-fat diet feeding. Pathol Biol (Paris) 56: 305-309, 2008.

9. Cannon B, Houstek J, and Nedergaard J. Brown adipose tissue. More than an effector of thermogenesis? Ann N Y Acad Sci 856: 171-187, 1998.

10. Cannon B, and Nedergaard J. Brown adipose tissue: function and physiological significance. Physiol Rev 84: 277-359, 2004.

11. Cinti S. Transdifferentiation properties of adipocytes in the adipose organ. Am J Physiol Endocrinol Metab 297: E977-986, 2009.

12. Colson C, Ghandour RA, Dufies O, Rekima S, Loubat A, Munro P, Boyer L, and Pisani DF. Diet Supplementation in omega3 Polyunsaturated Fatty Acid Favors an Anti-Inflammatory Basal Environment in Mouse Adipose Tissue. Nutrients 11: 2019.

13. Dowal L, Parameswaran P, Phat S, Akella S, Majumdar ID, Ranjan J, Shah C, Mogre S, Guntur K, Thapa K, Gesta S, Vishnudas VK, Narain NR, and Sarangarajan R. Intrinsic Properties of Brown and White Adipocytes Have Differential Effects on Macrophage Inflammatory Responses. Mediators Inflamm 2017: 9067049, 2017.

14. Faul F, Erdfelder E, Lang AG, and Buchner A. G*Power 3: a flexible statistical power analysis program for the social, behavioral, and biomedical sciences. Behav Res Methods 39: 175-191, 2007.

15. Fischer AW, Hoefig CS, Abreu-Vieira G, de Jong JM, Petrovic N, Mittag J, Cannon B, and Nedergaard J. Leptin Raises Defended Body Temperature without Activating Thermogenesis. Cell reports 14: 1621-1631, 2016.

16. Gatineau M HC, Holman N. and al. Public Health England: adult obesity and type 2 diabetes., edited by England $\mathrm{PH}$. 
https://www.gov.uk/government/uploads/system/uploads/attachment data/file/338934/Adult obesity and type 2 diabetes .pdf: 2014.

17. Ghandour RA, Colson C, Giroud M, Maurer S, Rekima S, Ailhaud GP, Klingenspor M, Amri EZ, and Pisani DF. Impact of dietary omega3 polyunsaturated fatty acid supplementation on brown and brite adipocyte function. J Lipid Res 2018.

18. Goto T, Naknukool S, Yoshitake R, Hanafusa Y, Tokiwa S, Li Y, Sakamoto T, Nitta T, Kim M, Takahashi N, Yu R, Daiyasu H, Seno S, Matsuda H, and Kawada T. Proinflammatory cytokine interleukin1 beta suppresses cold-induced thermogenesis in adipocytes. Cytokine 77: 107-114, 2016.

19. Hardwick JP, Eckman K, Lee YK, Abdelmegeed MA, Esterle A, Chilian WM, Chiang JY, and Song BJ. Eicosanoids in metabolic syndrome. Adv Pharmacol 66: 157-266, 2013.

20. Hotamisligil GS. Inflammation and metabolic disorders. Nature 444: 860-867, 2006.

21. Hotamisligil GS, Shargill NS, and Spiegelman BM. Adipose expression of tumor necrosis factoralpha: direct role in obesity-linked insulin resistance. Science 259: 87-91., 1993.

22. Jager J, Gremeaux T, Cormont M, Le Marchand-Brustel Y, and Tanti JF. Interleukin-1betainduced insulin resistance in adipocytes through down-regulation of insulin receptor substrate-1 expression. Endocrinology 148: 241-251, 2007.

23. Juge-Aubry CE, Somm E, Giusti V, Pernin A, Chicheportiche R, Verdumo C, Rohner-Jeanrenaud F, Burger D, Dayer JM, and Meier CA. Adipose tissue is a major source of interleukin-1 receptor antagonist: upregulation in obesity and inflammation. Diabetes 52: 1104-1110, 2003.

24. Karampela I, Christodoulatos GS, and Dalamaga M. The Role of Adipose Tissue and Adipokines in Sepsis: Inflammatory and Metabolic Considerations, and the Obesity Paradox. Current obesity reports 8: 434-457, 2019.

25. Kershaw EE, and Flier JS. Adipose tissue as an endocrine organ. J Clin Endocrinol Metab 89: 25482556, 2004.

26. Lagathu C, Yvan-Charvet L, Bastard JP, Maachi M, Quignard-Boulange A, Capeau J, and Caron M. Long-term treatment with interleukin-1beta induces insulin resistance in murine and human adipocytes. Diabetologia 49: 2162-2173, 2006.

27. Langin D. Recruitment of brown fat and conversion of white into brown adipocytes: strategies to fight the metabolic complications of obesity? Biochim Biophys Acta 1801: 372-376, 2010.

28. Larsen CM, Faulenbach M, Vaag A, Volund A, Ehses JA, Seifert B, Mandrup-Poulsen T, and Donath MY. Interleukin-1-receptor antagonist in type 2 diabetes mellitus. N Engl J Med 356: 1517-1526, 2007.

29. Locati M, Curtale G, and Mantovani A. Diversity, Mechanisms, and Significance of Macrophage Plasticity. Annu Rev Pathol 15: 123-147, 2020.

30. Lumeng CN, Bodzin JL, and Saltiel AR. Obesity induces a phenotypic switch in adipose tissue macrophage polarization. J Clin Invest 117: 175-184, 2007.

31. Masoodi M, Kuda $\mathbf{O}$, Rossmeisl M, Flachs P, and Kopecky J. Lipid signaling in adipose tissue: Connecting inflammation \& metabolism. Biochim Biophys Acta 1851: 503-518, 2015.

32. Odegaard JI, and Chawla A. The immune system as a sensor of the metabolic state. Immunity 38 : 644-654, 2013.

33. Okla M, Wang W, Kang I, Pashaj A, Carr T, and Chung S. Activation of Toll-like receptor 4 (TLR4) attenuates adaptive thermogenesis via endoplasmic reticulum stress. J Biol Chem 290: 26476-26490, 2015.

34. Okla M, Zaher W, Alfayez M, and Chung S. Inhibitory Effects of Toll-Like Receptor 4, NLRP3 Inflammasome, and Interleukin-1beta on White Adipocyte Browning. Inflammation 41: 626-642, 2018.

35. Patsouris D, Mandard S, Voshol PJ, Escher P, Tan NS, Havekes LM, Koenig W, Marz W, Tafuri S, Wahli W, Muller M, and Kersten S. PPARalpha governs glycerol metabolism. J Clin Invest 114: 94-103, 2004. 
36. Pisani DF, Beranger GE, Corinus A, Giroud M, Ghandour RA, Altirriba J, Chambard JC, Mazure NM, Bendahhou S, Duranton C, Michiels JF, Frontini A, Rohner-Jeanrenaud F, Cinti S, Christian M, Barhanin J, and Amri EZ. The K+ channel TASK1 modulates beta-adrenergic response in brown adipose tissue through the mineralocorticoid receptor pathway. FASEB J 30: 909-922, 2016.

37. Pohl J, Woodside B, and Luheshi GN. Leptin modulates the late fever response to LPS in dietinduced obese animals. Brain Behav Immun 42: 41-47, 2014.

38. Sachot C, Poole S, and Luheshi GN. Circulating leptin mediates lipopolysaccharide-induced anorexia and fever in rats. J Physiol 561: 263-272, 2004.

39. Sakamoto T, Takahashi N, Sawaragi Y, Naknukool S, Yu R, Goto T, and Kawada T. Inflammation induced by RAW macrophages suppresses UCP1 mRNA induction via ERK activation in 10T1/2 adipocytes. Am J Physiol Cell Physiol 304: C729-738, 2013.

40. Sauter NS, Schulthess FT, Galasso R, Castellani LW, and Maedler K. The antiinflammatory cytokine interleukin-1 receptor antagonist protects from high-fat diet-induced hyperglycemia. Endocrinology 149: 2208-2218, 2008.

41. Schaffler A, and Scholmerich J. Innate immunity and adipose tissue biology. Trends Immunol 31 : 228-235, 2010.

42. Schaffler A, Scholmerich J, and Salzberger B. Adipose tissue as an immunological organ: Toll-like receptors, C1q/TNFs and CTRPs. Trends Immunol 28: 393-399, 2007.

43. Seckinger $\mathbf{P}$, Lowenthal JW, Williamson K, Dayer JM, and MacDonald HR. A urine inhibitor of interleukin 1 activity that blocks ligand binding. J Immunol 139: 1546-1549, 1987.

44. Stienstra R, Tack CJ, Kanneganti TD, Joosten LA, and Netea MG. The inflammasome puts obesity in the danger zone. Cell metabolism 15: 10-18, 2012.

45. Tack CJ, Stienstra R, Joosten LA, and Netea MG. Inflammation links excess fat to insulin resistance: the role of the interleukin-1 family. Immunol Rev 249: 239-252, 2012.

46. Tilg $\mathbf{H}$, Zmora N, Adolph TE, and Elinav $\mathbf{E}$. The intestinal microbiota fuelling metabolic inflammation. Nat Rev Immunol 2019.

47. Umekawa T, Yoshida T, Sakane N, and Kondo M. Effect of CL316,243, a highly specific beta(3)adrenoceptor agonist, on lipolysis of epididymal, mesenteric and subcutaneous adipocytes in rats. Endocr J 44: 181-185, 1997.

48. van Asseldonk EJ, Stienstra R, Koenen TB, Joosten LA, Netea MG, and Tack CJ. Treatment with Anakinra improves disposition index but not insulin sensitivity in nondiabetic subjects with the metabolic syndrome: a randomized, double-blind, placebo-controlled study. J Clin Endocrinol Metab 96: 2119-2126, 2011.

49. Vijay-Kumar M, Aitken JD, Carvalho FA, Cullender TC, Mwangi S, Srinivasan S, Sitaraman SV, Knight R, Ley RE, and Gewirtz AT. Metabolic syndrome and altered gut microbiota in mice lacking Tolllike receptor 5. Science 328: 228-231, 2010.

50. Wellen KE, and Hotamisligil GS. Obesity-induced inflammatory changes in adipose tissue. J Clin Invest 112: 1785-1788, 2003.

51. Zu L, He J, Jiang H, Xu C, Pu S, and Xu G. Bacterial endotoxin stimulates adipose lipolysis via tolllike receptor 4 and extracellular signal-regulated kinase pathway. J Biol Chem 284: 5915-5926, 2009. 
Figure 1.
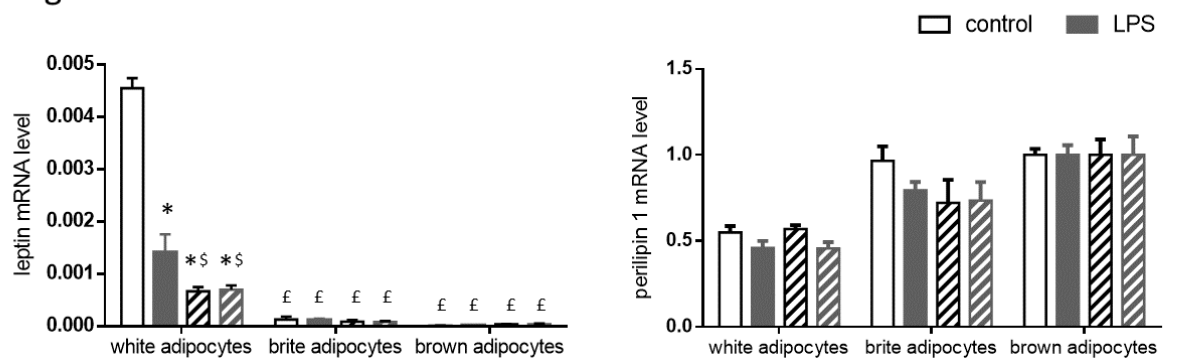

$\mathbb{Z}$ isoproterenol $\boldsymbol{Z}$ isoproterenol + LPS
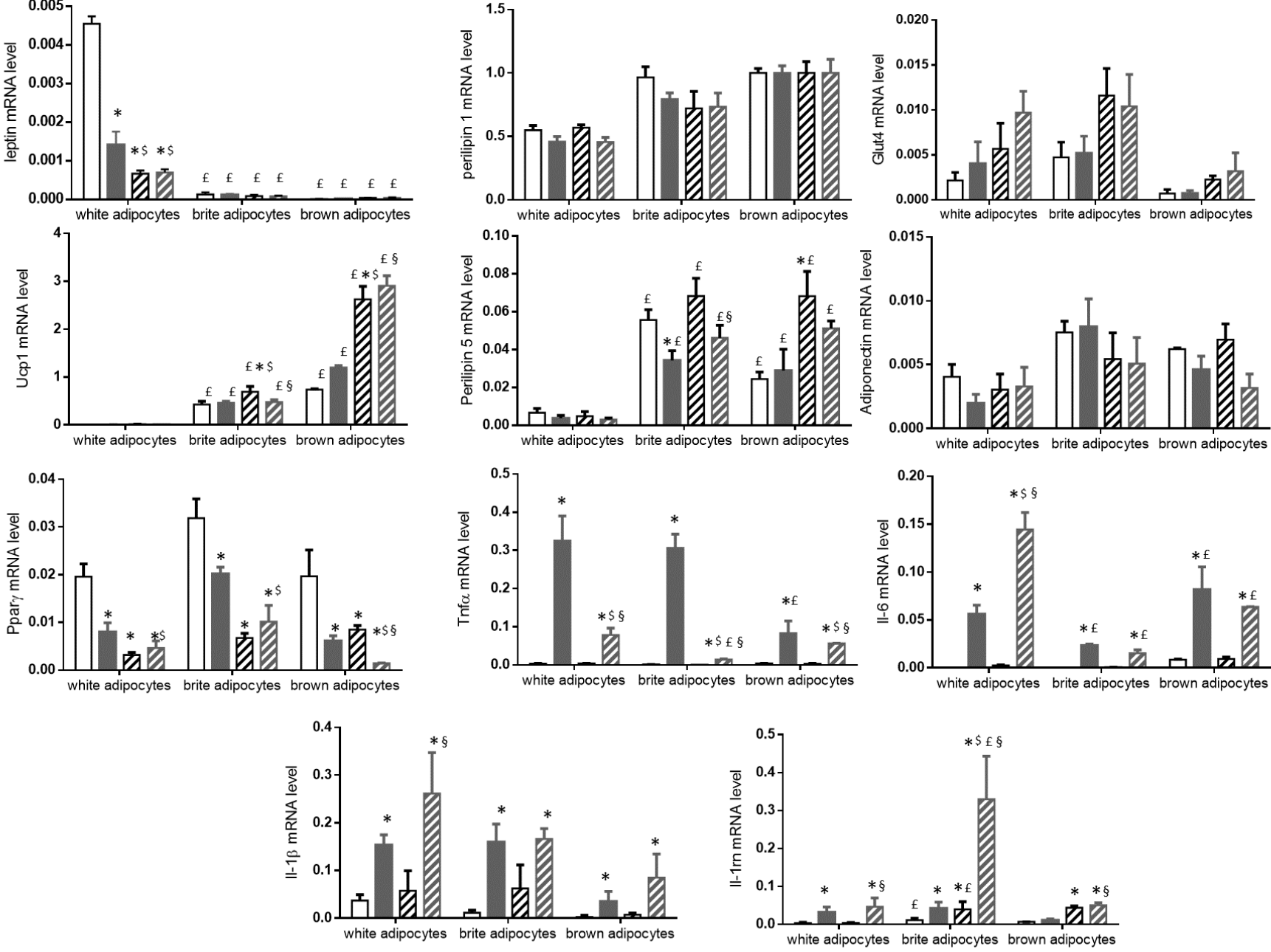
Figure 2.

A $\square$ control $\square$ LPS

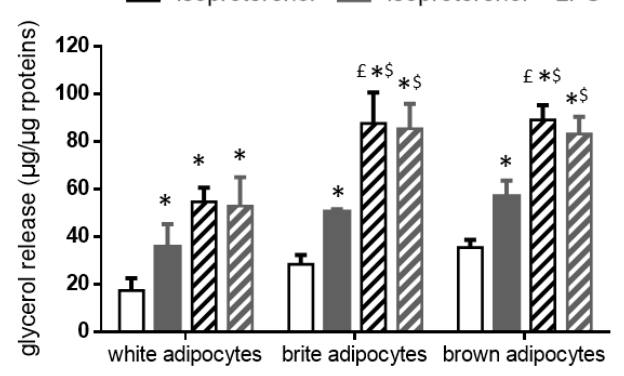

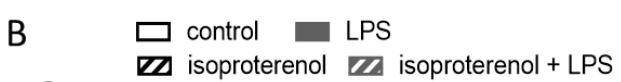

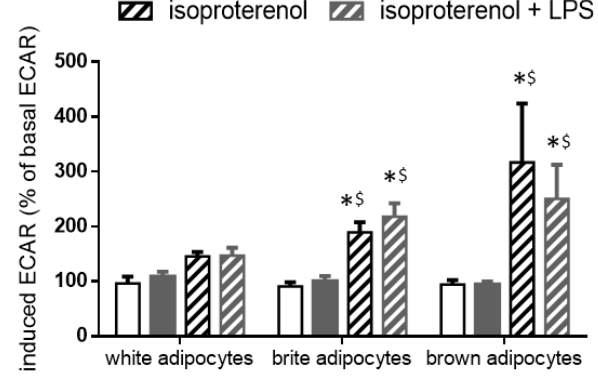

C

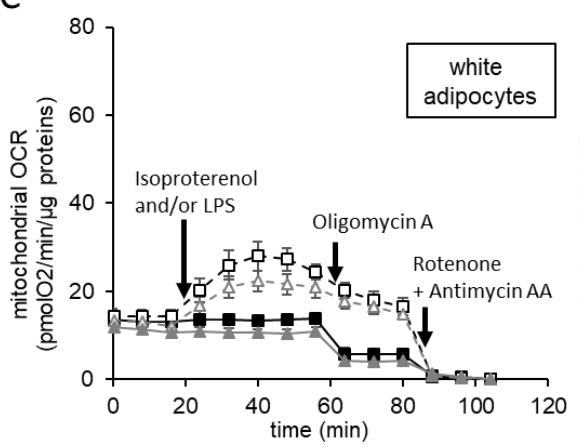

$\rightarrow-$ control $-\square-$ isoproterenol $--\Delta-$ isoproterenol + LPS $\longrightarrow$ LPS

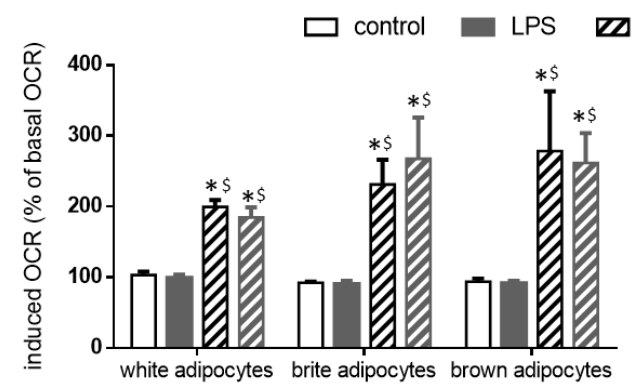

soproterenol $\mathbb{Z}$ isoproterenol + LPS
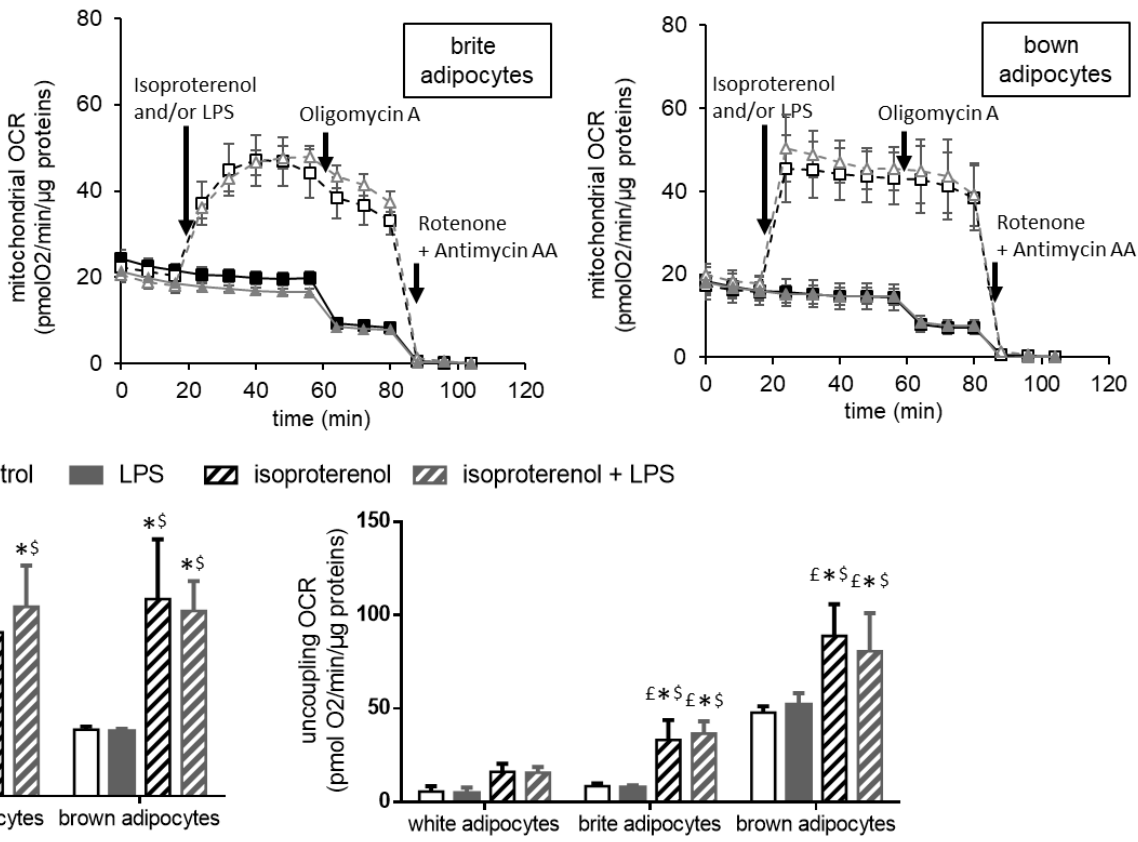
Figure 3.
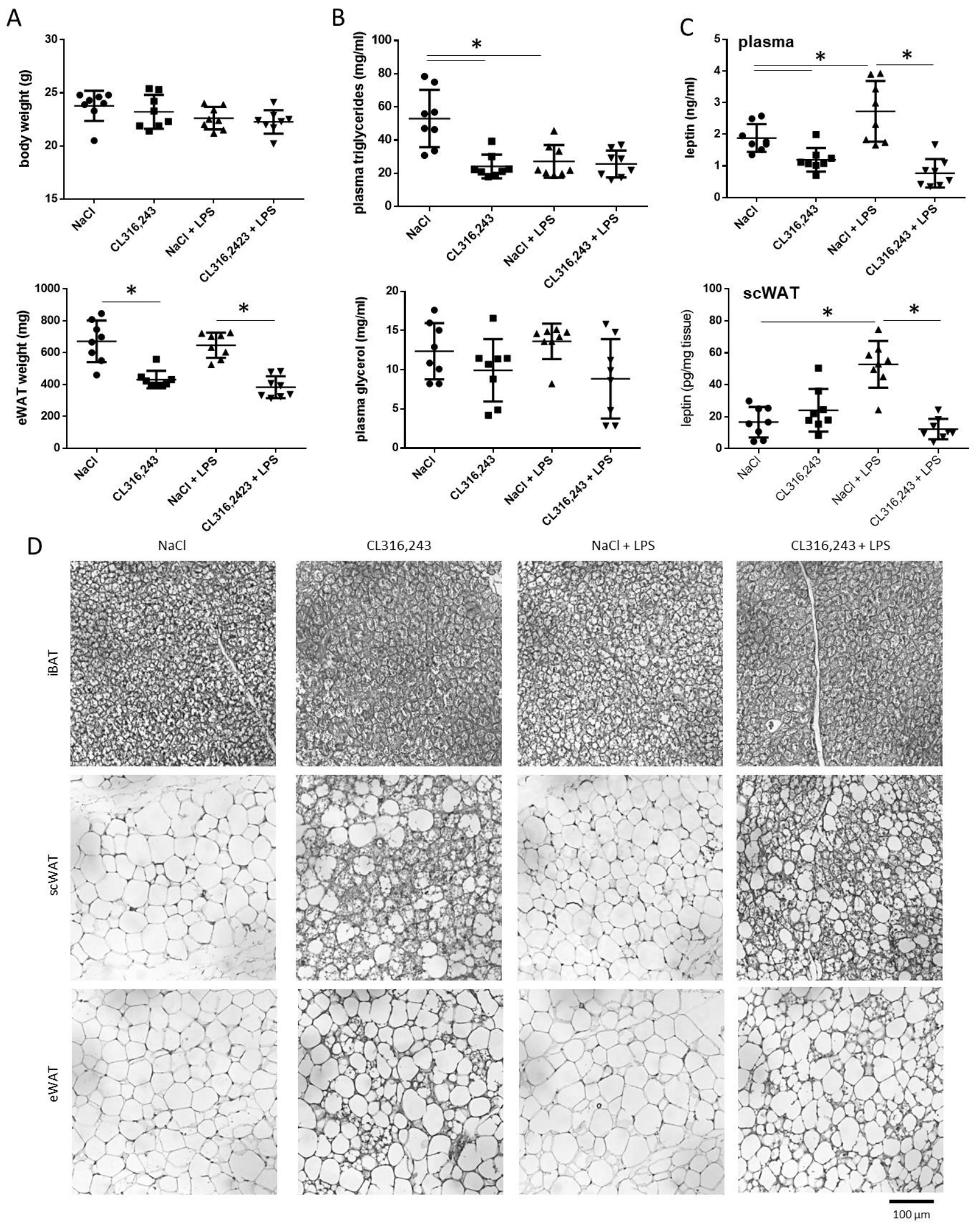
Figure 4.

A
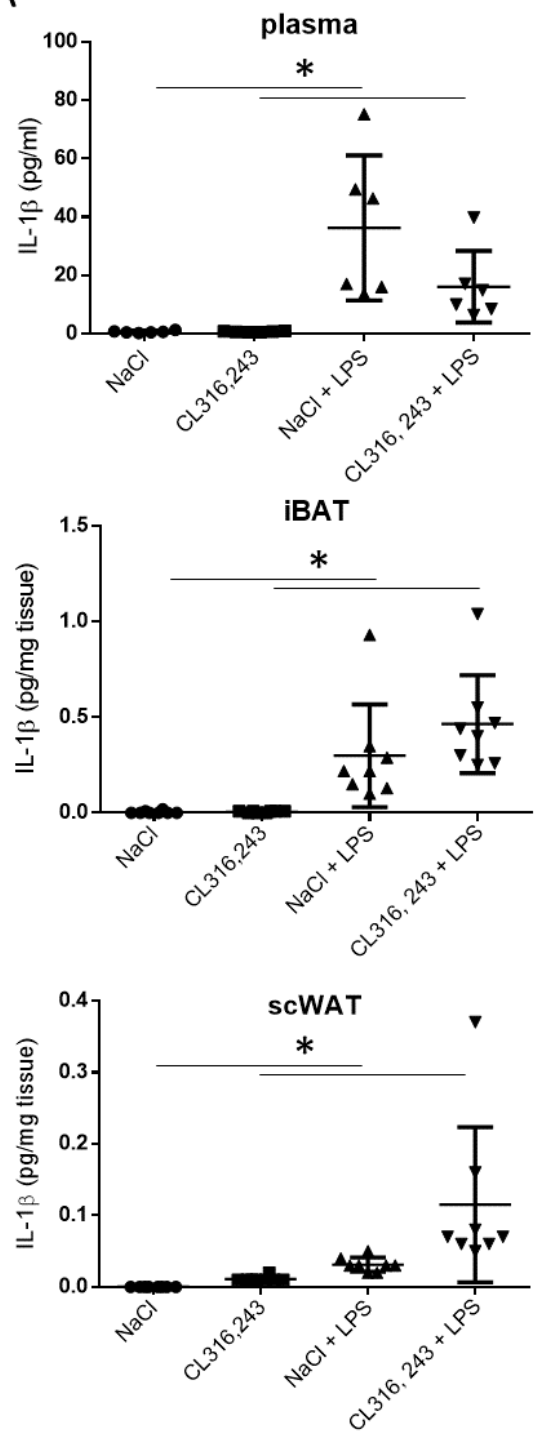

B
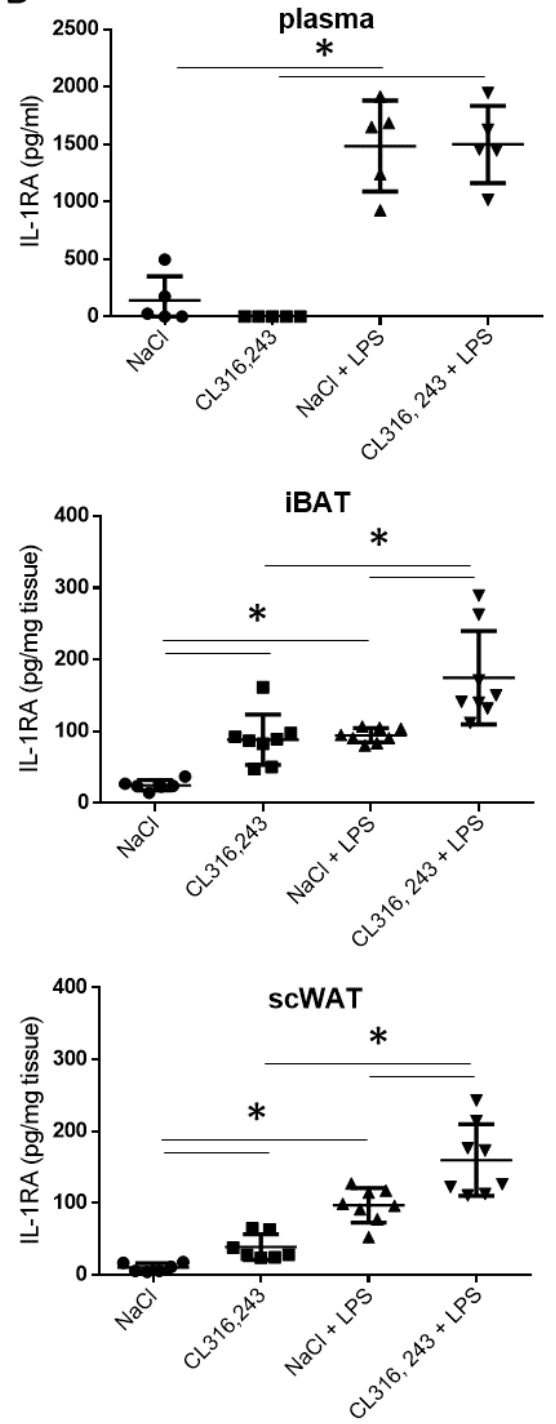
Figure 5.

\section{A IBAT}
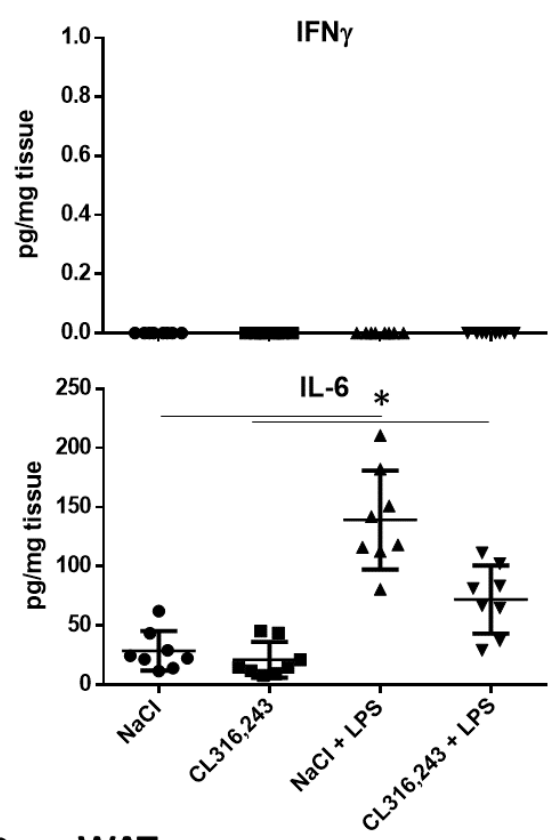

B ScWAT
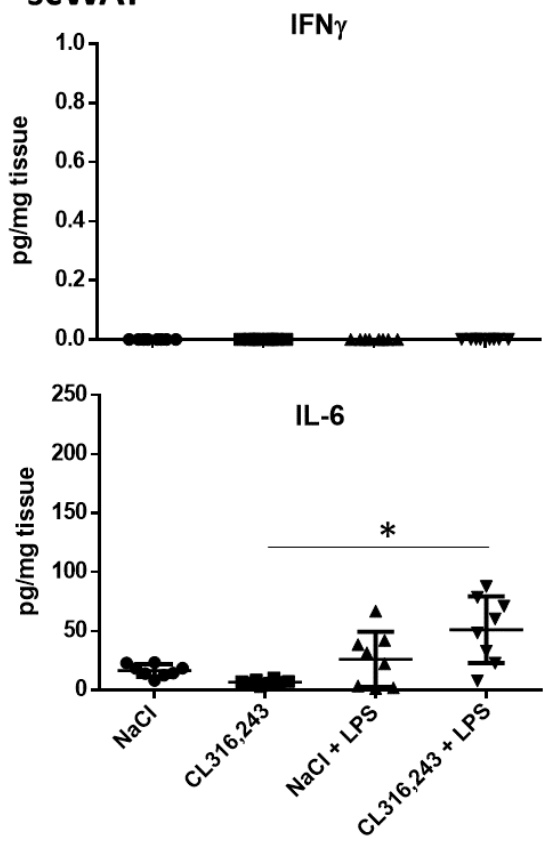
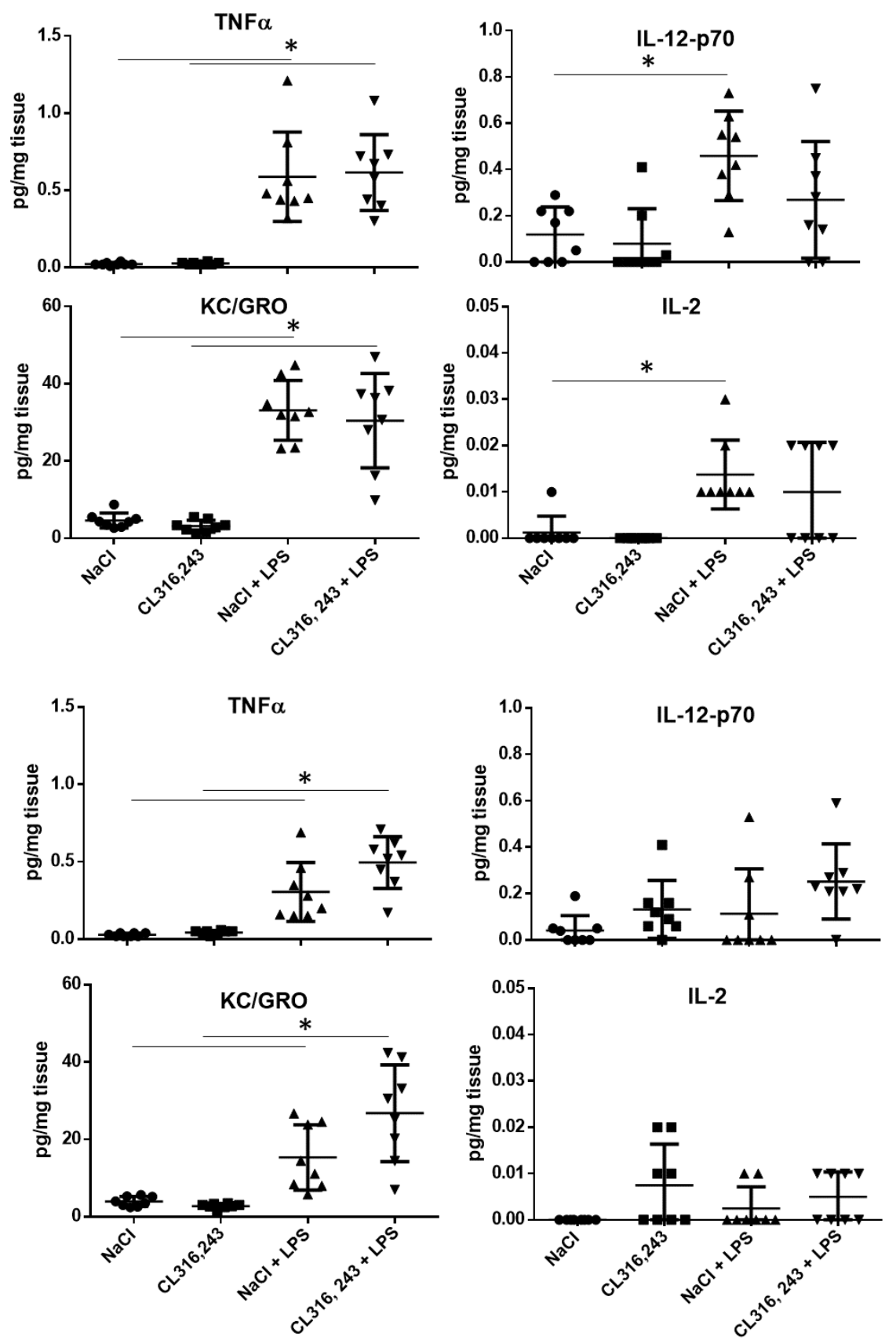